\title{
Experimental and Numerical Study of Lift-off Length and Ignition Delay of a Two-component Diesel Surrogate
}

\author{
Raúl Payri ${ }^{*}, a$, Juan Pablo Viera ${ }^{a}$, Yuanjiang Pei ${ }^{b}$, Sibendu Som ${ }^{b}$ \\ ${ }^{a}$ CMT-Motores Térmicos, Universitat Politècnica de València, Camino de Vera s/n, 46022 \\ Valencia, Spain \\ ${ }^{\text {b }}$ Argonne National Laboratory, 9700 S. Cass Avenue, Argonne, IL 60439, United States
}

\begin{abstract}
Understanding and controlling mixing and combustion processes is fundamental for the ever more demanding pollutant regulations and fuel consumption standards of direct injection diesel engines. The fundamentals of these processes haven been long studied from both experimental and numerical perspectives. As numerical models become more advanced, the need for adequate experimental data increases. Hence, experimental methodologies and scientific databases need to be enhanced with more quantitative, accurate, consistent, and reliable information in order to evaluate the models in a robust fashion. The present study seeks to enhance the current state-of-the-art by further evaluating the combustion performance of a twocomponent diesel surrogate for multi-dimensional compression ignition engine simulations, composed of $n$-dodecane and $m$-xylene. This surrogate is expected to better represent diesel fuel combustion than the standard Engine Combustion Network (ECN) fuel (n-dodecane), since it contains an alkyl-benzene which represents an important chemical class present in diesel fuels. Experiments and numerical simulations have been performed on lift-off length and ignition delay in a wide range of conditions for a single-hole injector from ECN. The experiments were carried out in a constant-pressure flow facility able of reproducing engine-like thermodynamic conditions. The experiments focused in characterizing the ignition delay through the Schlieren technique, and the lift-off length through $\mathrm{OH}^{*}$ chemiluminescence visualization, at ECN suggested test conditions. On the other hand, computational fluid dynamics (CFD) simulations were performed using a multi-flamelet representative interactive flamelet (mRIF) model by taking consideration of turbulence-chemistry-interaction ( $\mathrm{TCl}$ ) with a beta-function on the form of scalar probability density functions (PDFs). This model is evaluated extensively over a wider range of parametric variations in this study. Encouraging results were obtained compared to the experiments with regards to the predictions of ignition delay and lift-off length at different ambient temperatures, ambient densities and fuel-injection pressures. Under predictions were found at less reactive conditions, which leave room for improvement in the future.
\end{abstract}

\section{Keywords:}

Diesel injection; Engine Combustion Network; Ignition; Lift-off Length; mRIF; Reduced mechanisms, Diesel surrogates.

"Corresponding author. e-mail: rpayri@mot.upv.es. Phone number: +34 - 963879658 
Fuel injection, mixing, evaporation and combustion processes are the key to reduce pollutant formation and improving the efficiency of direct injection diesel engines [1]. To this end, engine research and development groups have been trying for decades to better understand and describe the fundamentals of these processes, including alternative fuels and combustion strategies [2][3]. Both experimental and computational approaches have brought important insight towards enhancing our understanding of the global and local processes governing fuel mixing and combustion. Computational tools, such as computational fluid dynamics (CFD) have proved their great potential [1][4], and are growing and improving every day by the incorporation of new models which are able to provide more detailed, time-resolved information. For example, due to the availability of computational resources, large eddy simulation (LES) [4][5] are becoming more frequent and reliable in the engine modeling community. However these models are not completely predictive and experimental data is necessary for further validation. Consequently, high-fidelity experimental data is necessary at the boundaries to properly initialize the simulation.

As CFD models become more complex and robust, the need for reliable, detailed, and highfidelity experimental data increases. Hence, experimental methodologies and scientific databases need to be enhanced with more quantitative, accurate, consistent, and reliable information [6][7][8] in order to properly evaluate the models.

The Engine Combustion Network (ECN) [6][7][9], is a worldwide initiative that brings together a group of research institutions that perform both experiments and numerical simulations, whose aim is to enhance the knowledge of spray and combustion processes at engine-relevant conditions. This initiative has permitted the construction of a large, public set of experimental data based on a particular operating condition: the so called "Spray A" condition, which is a lowtemperature combustion condition relevant to engines that use moderate EGR. The injector specifications are for modern advanced injection systems with high injection pressure capability. To properly predict combustion behavior, predictive chemical kinetic models are necessary. However, common transportation fuels contain a large number of components (each component usually comprises thousands of species and reactions) that would considerably complicate modeling, without necessarily adding scientific input to the analyses. Rather than developing mechanisms for all these components, representative fuel surrogates that consider only a small number of representative component classes are often chosen. Nevertheless, detailed chemical kinetic mechanisms for fuel surrogates are still quite large [10], so they need to be reduced in size for use in multi-dimensional engine simulations. Large reductions enable the inclusion of more components in a fuel surrogate to better mimic the real fuel properties in engine simulations. Together with the development in high-performance computing (HPC) capability

112 [11], complex chemistry mechanisms can now be applied for large scale, practical engine simulations. 
The present study envisages enhancing our understanding of multi-component diesel surrogate combustion at engine conditions using experimental and computational tools. The twocomponent diesel surrogate is composed of $n$-dodecane and $m$-xylene. This surrogate is expected to better represent diesel fuel combustion than the standard ECN fuel (n-dodecane) [12], since it contains an alkyl-benzene which represents an important chemical class present in diesel fuels. The detailed chemical mechanism of the binary mixture has 2885 species, compared to the pure n-dodecane with 2115 species, due to the inclusion of $\mathrm{m}$-xylene. In order to be computationally tractable, significant reduction was performed on the detailed mechanism in our previous study [13] while still maintaining the high chemical fidelity. The final reduced mechanism has 163 species and 887 reactions and has been validated extensively at different conditions.

The objective of the present study is to significantly enhance the experimental database for this two-component diesel surrogate [14][15] to facilitate more robust validation of the simulation tools. Experiments were carried out in a novel constant-pressure-flow facility (CPF) [16][17], able to reach $15 \mathrm{MPa}$ ambient pressure and $1000 \mathrm{~K}$ ambient temperature. The experiments focused in characterizing the ignition delay (ID) through the Schlieren technique [7][18][19][27], and the lift-off length $(L O L)$ through $\mathrm{OH}^{*}$ chemiluminescence visualization [20][21], at ECN suggested test conditions. The availability of such a robust and unique data-set provides a more effective crucible for model validation. CFD simulations were performed utilizing a multi-flamelet representative interactive flamelet (mRIF) combustion model described by the authors [13]. A reduced mechanism to mimic the combustion characteristics of the two-component mixture was first reduced and then validated under a limited set of ambient temperature conditions by the authors [13]. The second major objective of the current study is to further evaluate this

\section{Experimental set-up}

\subsection{The constant-pressure flow facility}

A constant-pressure flow test chamber [16][17] capable of mimicking the in-cylinder thermodynamic conditions of a diesel engine at the time of injection was used. This test rig presents the unique feature of obtaining nearly quiescent and, compared to other facilities such as constant volume chambers [6][8], steady thermodynamic conditions within the chamber. This is particularly useful for extensive experimental campaigns with parametric variations of thermodynamic test conditions. The quiescent and steady conditions provide a high test repetition rate-also reducing the effective test time for a given set of test conditions-and enhance the shot-to-shot precision of the tests performed. 
In Figure $1 \mathrm{a}$ sketch of the facility layout is provided. The boundary conditions have been well characterized in [6] and a complete description of the facility is given in [17][22]. In order to measure correctly the temperature at the conditions tested, radiation heat transfer should be accounted for [23].

\subsection{The injection system}

The injection system consists of commercial components: a high pressure volumetric Bosch CP3 pump driven by an electric motor; a common rail with pressure regulator controlled by a PID system; and a special injector holder which is used to keep constant the injector tip temperature [22] though the whole test matrix. Fuel pressure is monitored with a piezo-electric pressure sensor sampled at $100 \mathrm{kHz}$ to guarantee the correct pressure conditions at the time of injection and to verify that the transient response complies with ECN requirements and not influence the results.

The injector employed, is part of the ECN injector dataset (ref: \#210675 [9]). It features a singlehole axial nozzle which simplifies visualization and localizes the problem into one single spray. Moreover, it is important to note that the internal geometry [24] and hydraulic behavior of ECN injectors have been well characterized and the data is published in [9] and available online. The fuel surrogate utilized for this study (from this point forward, referred to as SR23) is composed of $77 \%$ n-dodecane and $23 \% \mathrm{~m}$-xylene (by volume).

\subsection{The test matrix}

The test matrix is summarized in Table 1. It includes the Spray $A$ operating conditions $\left(T_{a m b}=\right.$ $900 \mathrm{~K}, \rho_{\text {amb }}=22.8 \mathrm{~kg} / \mathrm{m}^{3}, p_{\text {rail }}=150 \mathrm{MPa}, \mathrm{O}_{2}=15 \%$ (by volume) and parametric variations of the main variables (ambient temperature, ambient density and injection pressure) as suggested by ECN Working Group.

\subsection{Optical techniques and processing methods}

\subsubsection{Lift-off length}

The lift-off length $(L O L)$ was measured capturing the signal from $\mathrm{OH}^{*}$ chemiluminescence following the ECN standard methodology [18] [20]. An ICCD camera (Andor I-star) fitted with a $100 \mathrm{~mm}$ f/2.8 UV lens and a $310 \pm 5 \mathrm{~nm}$ interferometric filter was used with a constant intensifier gating time widow included between 2.0 and $5.0 \mathrm{~ms}$ ASOI. This way, the steady part of the injection was averaged on-chip along the injection event minimizing the effects of local turbulent flame behavior and shot-to-shot dispersion. 
To better illustrate the LOL estimation algorithm, Figure 2-top presents the raw image obtained at Spray A conditions for a single injection, while Figure 2-bottom shows the intensity profiles constructed from the upper and lower halves of the raw image, the intensity profile constructed from the repetition-average image and its corresponding peak value. The lift-off length is then determined by finding the distances between the injector tip and the first axial locations above and below the spray centerline with intensity greater than $50 \%$ of a pre-selected intensity peak. The average of these two axial distances is defined as the LOL.

Three different LOL are plotted as dashed lines over the raw image, each corresponding to a value calculated from a different intensity threshold. The thresholds selected were $10 \%, 25 \%$ and $50 \%$ of the repetition average peak stored for these test conditions, and the result clearly underlines how the threshold definition can affect the experimental LOL reported. From this point forward, LOL results reported for each test condition correspond to a threshold of $50 \%$ of the repetition-average intensity peak for those conditions.

\subsubsection{Ignition Delay}

Prior to detailing the processing algorithm that was applied to determine the auto-ignition delays, it is convenient to define two parameters that characterize the ignition process as found in the literature [19][25].

$\rightarrow$ Start of cool flames (SoCF): time elapsed between the Start of Injection (SOI) and the first onset of chemical reactions-low temperature heat release.

$\rightarrow$ Start of high temperature reactions or Second Stage Ignition (SSI): this parameter, normally known referred to as simply ignition delay is the time at which the high temperature heat release reactions start, with respect to the SOI.

Schlieren imaging has been successfully employed several times to characterize different aspects of the diesel spray [7][16][19][26][27]. It is a valuable technique to identify refractive index gradients in transparent mediums [26]. For vaporizing diesel [7][16][27][28][29] and gasoline [30] sprays, this technique is able to depict the boundary between vaporized fuel and ambient gases because: (1) refractive index differ between the fuel and ambient gases and (2) density gradients are created in mixture as the vaporized fuel spray cools the mixture. With adequate image acquisition systems, this technique permits to characterize the spray even for fast response injectors and transient events [16]. Using Schlieren setups, Pickett et al. [27] and later Lillo et al. [19] reported that the onset of cool flames can be observed as a temporal disappearance of the spray in the tip region. Authors attribute this phenomenon to the changes in chemical composition and temperature of the mixture that takes place in this early phase of the ignition. The refractive index of the mixture changes and for a transient period is very close to that of the surrounding gas, then becoming virtually invisible to the Schlieren setup. Bardi et al. [7] observed consistently this phenomenon in different facilities and compared the different experiments based on the measured spray tip penetration. 
In order to analyze the disappearance phenomenon observed through the Schlieren setup in a factual way, and to compare the event under different test conditions, a special image processing sequence was developed by the authors in [18], which can be summarized as follows:

$\rightarrow$ Background correction: every image processed is corrected to eliminate the background

To better illustrate the different stages of the ignition process and the algorithm utilized in this study, Figure 3 presents these two metrics along the injection event for both inert and reacting sprays. Figure 3-top presents the total image intensity, denoting a clear difference between the two cases. It is important to remember that the total intensity calculation is done to the inverted and background-corrected image, so an increase in this metric implies a larger and/or darker spray in the raw images. Although the difference may be noted by tracing this metric, it is actually more convenient to trace its derivative, the total image intensity increment $\Delta y$, shown in Figure 3-bottom. In this case, the difference between the curves marks very well the development of the ignition process, which can be completely characterized for many test conditions [18]. After the ignition process, the steady region is reached, where diffusion combustion continues for the reacting spray, thus separating it steadily from the inert spray in terms of these two metrics. test conditions studied in [18] and in this study. This implies that detecting the SSI is always 
possible, but the same cannot be affirmed of the SoCF. The correct detection of the SoCF needs, for many test conditions, the corresponding inert spray study. For some other conditions, it is very difficult to detect properly. Therefore, this study focuses only on characterizing the SSI behavior of the SR23 fuel.

Authors in Ref. [18] demonstrate that the local maximum in the $\Delta y$ curve (shown in Figure 3bottom) matches the SSI delay detected by broadband chemiluminescence visualization of the spray. Hence, the algorithm consists in detecting the local maximum in the $\Delta y$ curve constructed for each test repetition, to then calculate a single repetition average value. All experimental results reported in this study then show error bars which correspond to the standard deviation obtained from this repetition average.

282

The advantages and limitations of utilizing Schlieren images to determine ID were previously highlighted by the authors [18]. It is important to point out that utilizing the Schlieren approach in this study permits (1) to continue developing this interesting technique for determining the SSI of reactive sprays and (2) to obtain comparable results with the different fuels presented here and in the Ref. [18].

\subsection{Optical setup}

The $\mathrm{OH}^{*}$ chemiluminescense setup consisted of simply visualizing the spray flame. On the other hand, the Schlieren setup consisted of a single pass, diaphragm-controlled setup. Cameras were located on either side of the chamber to visualize the spray from opposing directions. Since the Schlieren collimated light beam is required to cross the complete chamber, the $\mathrm{OH}^{*}$ chemiluminescense camera had to be inclined slightly off axis so not to block the collimated beam. However, the angle is small at $7^{\circ}$, and the possible effects are accounted for by properly correcting the images. The rest of the details of the optical setup are summarized in Table 2.

\section{Computational Fluid Dynamic Modeling Approach}

The simulations were performed in a 3D, constant-volume, cubic combustion chamber with dimensions of $108 \mathrm{~mm}$ (on each side) using a commercially available CFD code called CONVERGE [32]. The details of the computational models can be found in our previous study [33] and will only be briefly discussed here. The liquid phase was treated with a traditional Lagrangian discrete phase model along with the "blob" injection method [34]. The droplet secondary breakup and collision processes were modeled using Kelvin-Helmholtz and Rayleigh-Taylor (KH-RT) model [35][36] and "no time counter" algorithm [37], respectively. Multi-component droplet evaporation was accounted by using Frossling correlations [38] for each of the components. Dynamic drag model [39] was used to model the droplet drag. The Renormalization Group (RNG) k- $\varepsilon$ turbulence model [40] was also used in these simulations. 
311 The gas phase is treated as continuous Eulerian phase and the governing equations are solved 312 on a CFD mesh. The CONVERGE code uses an innovative, modified cut cell Cartesian 313 technique to generate the mesh at run time. The mesh is automatically refined at certain regions 314 based on the physics of the problem. This is achieved using adaptive mesh refinement (AMR). 315 The minimum cell sizes of $0.25 \mathrm{~mm}$ are maintained for these RANS calculations following the 316 best practices identified by Senecal and Som [41], keeping in mind both accuracy and 317 computational cost. A minimum resolution of $0.25 \mathrm{~mm}$ results in grid-convergence to spray and 318 combustion characteristics such as ID and LOL.

320 The Representative Interactive Flamelet (RIF) [42] combustion model, which considers 321 turbulence-chemistry interactions (TCl) by assuming a presumed beta PDF for scalars was coupled to an unsteady Reynolds averaged Navier-Stokes (RANS) solver. Kundu et al [33]. recently implemented and tested the mRIF model for a single-component fuel (n-dodecane) under ECN conditions [32]. Thereafter Pei et al. [13] extended the mRIF implementation for the multi-component SR23 mixture by using the reduced chemical kinetic model consisting of 163 species and 887 reactions. The reduced mechanism was extensively compared to the detailed mechanism by Pei et al. [13]. Following the recommendations from Kundu et al. [33] and Pei et al. [13], more than 20 flamelets were used in the simulations, keeping in mind both computational accuracy and wall-clock times since higher number of flamelets typically increase the computational cost. The liquid mixture properties for $n$-dodecane and $m$-xylene were obtained from National Institute of Standards and Technology (NIST) [43]. The ignition delay in the simulation is defined as the time from the SOI to the time where maximum temperature rise happens following the standard definition of ECN workshop [44] [45]. The lift-off length in the simulation is defined as the axial distance from nozzle exit to $14 \%$ of maximum $\mathrm{OH}$ in the quasi-steady state. The choice of this definition is due to the absence of $\mathrm{OH}^{*}$ in the mechanism and it was also found that $14 \%$ of $\mathrm{OH}$ correlated well with $50 \%$ of $\mathrm{OH}^{*}$ level-off value [46]. 


\section{Results}

The experimental measurements along with the computed results at different ambient temperatures, ambient densities and fuel injection pressures are reported in this section. First, a brief discussion of experimental observations is presented, followed by a comparison of simulation and experimental results. Lastly, further analysis of the simulations is shown followed by some conclusions.

\subsection{Experimental observations}

As explained in section 2.4, for the LOL estimation each test condition is associated with an intensity threshold value calculated as $50 \%$ of the peak value extracted from the repetition average intensity profile. Figure 4 illustrates how these thresholds depend on some of the different variables tested. Note that the complete test matrix is not shown for the sake of clarity.

All intensity thresholds increase with the injection pressure in a linear fashion...As injection pressure increases, so does the spray penetration and the mixing rates [47] before ignition. This implies a more developed mixing at the time of ignition, so the stabilized LOL is not only longer (as can be seen in the next section) but it also features a stronger $\mathrm{OH}^{*}$ chemiluminescence signal next to it, associated with a stronger and/or larger pre-mixed combustion region. It is important to mark that the intensity of the signal detected at a particular spatial location in the image plane is the result of the combination of $\mathrm{OH}^{*}$ chemiluminescence intensity and line-ofsight integration of this phenomena across the spray at this particular location. The amount of fuel-air premixing determines not only the physical conditions at the time and location of ignition but also the radial extent of the pre-mixed combustion region, which indeed affects the intensity of the line-of-sight signal detected. A similar effect is observed when slightly reducing densities: the spray penetrates faster, ignition delays are longer, and therefore the pre-mixed combustion region near the $\mathrm{LOL}$ is stronger and/or larger. The lower ambient temperature shown $(800 \mathrm{~K})$ also shows this when compared against the higher temperature case $(900 \mathrm{~K})$ : slightly lower temperatures render longer ignition delays and in turn, increase the pre-mixed combustion region intensity.

Nonetheless, it is important to remember that the detected pre-mixed region combustion intensity—and thus, the detected $\mathrm{OH}^{*}$ chemiluminescence signal intensity peak near the LOLdepends not only on the amount of fuel-air premixing but also on the thermodynamic state of the mixture [25]. Therefore, the same variables such as density, temperature, and oxygen concentration (which was invariant in this study) influence the same phenomenon in different ways. This means that the effect of each of these variables over the final intensity threshold is not linear and, for example, reducing ambient temperature further to $750 \mathrm{~K}$ renders intensity thresholds much lower than those of $900 \mathrm{~K}$. In this case, the contribution of more pre-mixing 
time allowed by longer ignition delays is suppressed by the great reduction in combustion intensity due to less reactive condition.

Figure 5-top and 6-top present the time evolution of the parameter $y$ : as the injection event develops and the spray grows larger, the total intensity increases. At the SoCF, the spray becomes transparent and the total intensity trend changes. Afterward, as the spray tip appears again in the Schlieren image, the total intensity continues to increase as a consequence of the second stage ignition. The two changes in the slope of the curve correspond to the two peaks observed in Figure 5-bottom and 6-bottom, where the total image intensity increment is plotted. It is important to point out that the actual $y$ value collected at a given time frame is a combination of spray size and inverted image intensity. If the spray grows larger, so will the sum of the intensities of all the pixels contained, but the same is true if it gets brighter in the processed image (hence, darker in the actual Schlieren setup). Therefore, the parameter $\Delta y$ indicates changes in $y$ due to both changes in intensity and size, which increases the sensitivity of the method to detect an ignition situation.

Figure 5 shows the behavior of the ignition process as injection pressure is increased gradually. In Figure 5-top, the total intensity presents an almost linear response to the injection pressure in the stationary part of the injection event, which is expected as the higher injection pressure spray penetrates (thus, grows in total area) faster. Figure 5-bottom shows the same for the stationary part of the injection, where each injection pressure stabilizes at a different constant stationary value after the ignition, scaled with injection pressures. However, a clear influence of the injection pressure over the complete ignition process can be observed, which underlines the influence of the mixing process on the ignition delay, as has been observed previously in [18][48]. The SoCF, which occurs when the parameter $\Delta y$ starts to decrease rapidly before the first important local minimum, is shifted to earlier timings as injection pressures increase and with it, the SSI. Moreover, the ignition is faster in timing and duration, with the local maximumassociated with the high temperature heat release-increasing noticeably as well. This is in agreement with what is presented in Figure 4 for the thresholds, and in both cases the effect of the injection pressure is clearly underlined: the injection pressure enhances the amount of fuelair premixing, thus increasing the pre-mixed combustion phase intensity. This trend is similar with what the authors presented for pure n-dodecane in Ref. [18] and similar test conditions. Nevertheless, no major changes in the shape of the ignition event, as acquired by the optical

414 On the other hand, Figure 6 depicts the behavior of the ignition process as ambient temperature 415 is incremented gradually. In Figure 6-top, significant differences in the ignition events and 416 ignition duration can be observed. Unlike the effect of injection pressure shown in Figure 5, in 417 this case the shape of the ignition events is greatly affected by the ambient temperature, which 418 is expected. This is better backed by Figure 6-bottom, where the total intensity increment clearly 
shows the difference in ignition delays and ignition process duration and shape for the different temperatures. As ambient temperature is decreased, the ignition delay increase and the premixed combustion phase grows in intensity and duration, as the authors also found for pure ndodecane in Ref. [18] for similar test conditions. One important feature to point out is that, after the ignition event is completed, all curves continue with the same inclination (top), or constant value (bottom). This indicates that the spray development in the stationary part of the injection is not significantly affected by the ambient temperature, in terms of size (area) and refractive indexes, which is what the optical technique is detecting. Also, it is important to note that, as ambient temperature is increased, the SoCF becomes harder to detect since the local minimum is smaller and the process is much faster. In fact, if the ambient reactivity is greatly increased (i.e. with either higher temperature or with higher oxygen concentration) the local minimum may completely disappear, leaving just the local maximum so that it is only possible to detect the SSI, but not the SoCF. On the other end of the temperature range, Figure 6-bottom clearly shows that the ignition process for the two lowest temperature cases behaves differently than those of higher temperature, featuring local maximums before the rapid decrease associated with the SoCF. The process is observed in the images as the spray becoming darker before the typical transparent stage seen in Schlieren images of reactive sprays. This suggests that the low-temperature heat release reactions/mechanisms may be quite different from those of higher temperature cases. This behavior is also present in the results presented by the authors for pure n-dodecane and similar test conditions in Ref. [18].

\subsection{Simulation and experimental results}

Figure 7 shows the comparison of ignition delay and LOL between experiments and simulations at different ambient temperature conditions. In general, simulations are able to capture the experimental trends very well for both these parameters. Excellent quantitative agreement is also observed between simulation and experiments for temperatures at and above $850 \mathrm{~K}$. At the lesser reactive conditions of 750 and $800 \mathrm{~K}$, the ignition delay is underpredicted, consequently resulting in lower LOL values. The underpredictions at less reactive conditions may be attributed to the following two reasons: (1) for the two-component mixture due to the lack of experimental data for the liquid spray and mixing, liquid length and vapor penetration are only validated at the more reactive condition [13]. Hence, the spray set-up may be a source of some uncertainty at the lesser reactive conditions, (2) another possible reason is the chemical kinetic mechanism at the lower temperature conditions. Absence of good low temperature chemical kinetic mechanisms has been a concern for the community for several years. While improving the kinetic mechanism is beyond the scope of the current study, the authors will pursue this in future studies.

The ignition delay and lift-off length comparison between experiment and simulation at different ambient density conditions are presented in Figure 8 . The predictions at higher ambient 
observed at the lower ambient density of $7.6 \mathrm{~kg} / \mathrm{m}^{3}$ for ignition delay. Although experimental LOL data is not available at this low ambient density condition, LOL is also expected to be under-predicted since ignition delay was under-predicted. Although there is no experimental data at $45.6 \mathrm{~kg} / \mathrm{m}^{3}$, simulated values are shown for the sake of completion. The under predictions at the lower ambient density are attributed to the fact that the spray set-up was not validated due to the lack of experimental data at this condition.

Injection pressure affects the turbulence and mixture formation, thus influences the turbulencechemistry interactions. Higher injection pressure will increase velocity and lead to faster spray break-up, evaporation and intense mixing with surrounding air. A more rapid formation of ignitable mixture is expected with increase in injection pressure. This trend is observed in the measurements shown in Figure 9, where higher injection pressure results in lower ignition delay. The simulations can capture this trend very well, although the quantitative values are underpredicted, especially at the lower injection pressures. The lift-off length comparison is also presented in Figure 9. The experimental trend is well-captured by the simulation, especially at the higher injection pressures, although minor over-predictions at the lower injection pressures are observed. The under predictions at the lower injection pressure is attributed to the fact that the spray set-up was not validated due to the lack of experimental data at this condition.

Advanced turbulence models such as LES will be able to predict the mixing field better when compared to RANS. Future studies will also explore LES combustion simulations with this multicomponent surrogate to further improve the predictions, especially at lower ambient temperatures, densities, and injection pressures.

\subsection{Further analysis of the simulation results}

Following extensive validation of the simulation approach, further insights can be gained into the mixing and combustion processes by further post-processing the simulation results. It is well known that the ignition delay and the steady LOL are closely related [48]. This further affects the equivalence ratio at the lift-off location. The following analysis plots equivalence ratio at lift-off locations at different ambient conditions. Figure 10 plots the flame structure colored by $\mathrm{OH}$ mass fraction for the Spray A $900 \mathrm{~K}$ condition at $3.2 \mathrm{~ms}$ showing the lift-off length and lift-off location away from the axis of injection. This image is provided to help the reader visually locate the regions for which equivalence ratios are plotted in Figures 11 and 12.

Figure 11 shows the axial equivalence ratio along the spray centerline at the time LOL has reached a quasi-steady state for different ambient temperature conditions. The equivalence ratios at lift-off locations (hollow markers) away from the axis are also shown. The axial profiles of the gas-phase equivalence ratio are quite similar for different ambient conditions (as 
expected), although the lift-off locations are further upstream at higher ambient temperatures. It is interesting to note that the equivalence ratio at the lift-off location (away from the axis) is quite similar ( 0.68) for the different ambient temperatures. The flame is stabilized in a fuel-lean region under these conditions. This is consistent with the observations of Hawkes et al. [49][50], which suggested that this is probably because of the lowering of velocity components as moving further away from the axis.

Figure 12 shows the axial equivalence ratio along the spray centerline at the time LOL has reached a quasi-steady state for at different ambient density conditions. The equivalence ratios at lift-off locations (hollow markers) away from the axis are also plotted. The axial profiles of the gas-phase equivalence ratio are quite different at different ambient densities although the lift-off locations are further upstream at lower ambient densities. The equivalence ratio values at lift-off location are again quite similar to each other, i.e., around 0.68. Similar findings were also observed for different injection pressures and hence not shown here.

After extensive validation and discussion of results, the computational cost is provided here briefly. The most expensive calculation took about 540 wall-clock hours on 48 processors to reach the end-of-injection. The least expensive calculation took about 65 wall clock hours on 32 processors. These simulations were able to accommodate an advanced turbulent combustion model together with a relatively large chemical kinetic mechanism due to the availability of the computational resources.

521

522

\section{Summary and Conclusions}

This study focused on significantly extending the database for ignition delay and flame lift-off length for a multi-component diesel fuel surrogate consisting of $n$-dodecane and $m$-xylene in a constant volume spray combustion vessel under engine conditions. Experiments were performed using a single-hole ECN injector. The high-fidelity and extensive database allowed for more comprehensive assessment of the simulation methodologies. A reduced chemical kinetic mechanism for the two-component surrogate together with the mRIF turbulent combustion model were mainly assessed against this dataset. Some key conclusions are as follows:

1) The experiments successfully captured the effects of injection pressure, ambient temperature and ambient density over the ignition delays and LOL of the proposed surrogate fuel when injected through an ECN single orifice injector. Increasing ambient temperature or ambient density decreases both the ignition delays and the LOL. Increasing the injection pressure produces a gradual decrease in ignition delays which underlines the importance of air-fuel mixing. However, although ignition delays are decreased, injection pressure increases injection velocities, so the LOL increases considerably. 
2) The LOL threshold study shows that the effects of ambient temperature and ambient density are over the $\mathrm{OH}^{*}$ chemiluminescen intensity peak near the $\mathrm{LOL}$ are not linear, but a compromise between the mixing state and ambient reactivity. Hence, the proper threshold for each test condition has to be determined.

3) The Schlieren technique proved to be a valuable approach to the detection of the second stage ignition (SSI). Moreover, the effect of ambient temperature over the shape of the ignition process was presented. The ignition behavior showed to be different depending on temperature, which suggests that the low-temperature heat release mechanisms may be quite different from those of higher temperature cases.

4) The simulations were able to capture all the experimental trends very well for different ambient temperature, ambient density, and injection pressure conditions.

5) The flame LOL and ignition delay were well captured at higher ambient temperatures, however, at lower ambient temperature, significant room for improvement still remains. This highlights the need for better chemical kinetic mechanisms to account for the low temperature chemical kinetics.

6) The flame LOL and ignition delay were also well captured at higher ambient density and injection pressure conditions. However, at lower ambient density and lower injection pressures the simulations tend to underpredict both ignition delay and LOL. This may be an artifact of the spray set-up and validation under these conditions. This further motivates the need for non-combusting data for the two-component surrogates for the large range of conditions.

7) For all the injection and ambient conditions explored in this study, although lift-offlengths are quite different, it is interesting to note that the equivalence ratios at lift-off locations were quite similar. 


\section{Acknowledgements}

This work was sponsored by "Ministerio de Economía y Competitividad" of the Spanish Government in the frame of the Project "Comprensión de la influencia de combustibles no convencionales en el proceso de injección y combustión tipo diesel', Reference TRA201236932. Additionally, the optical equipment used for the project was purchased with funding from Ministerio de economia y competitividad FEDER-ICTS-2012-06.

571 The submitted manuscript has been created by UChicago Argonne, LLC, Operator of Argonne

572 National Laboratory ("Argonne"). Argonne, a U.S. Department of Energy Office of Science 573 laboratory, is operated under Contract No. DE-AC02-06CH11357. The U.S. Government retains

574 for itself, and others acting on its behalf, a paid-up nonexclusive, irrevocable worldwide license

575 in said article to reproduce, prepare derivative works, distribute copies to the public, and

576 perform publicly and display publicly, by or on behalf of the Government.

577 The research was funded by DOE's Office of Vehicle Technologies, Office of Energy Efficiency

578 and Renewable Energy under Contract No. DE-AC02-06CH11357. The authors wish to thank

579 Gurpreet Singh and Leo Breton, program managers at DOE, for his support.

580 We gratefully acknowledge the computing resources provided on "Blues," a 5000+ core

581 computing cluster operated by the Laboratory Computing Resource Center at Argonne National 582 Laboratory.

583 The authors would finally like to thank Jose Enrique Del Rey and Michele Bardi for their 584 collaboration in the setup of the experiments and laboratory work. 


\section{References}

[1]. R. Mobasheri, Z. Peng, S. M. Mirsalim, Analysis the effect of advanced injection strategies on engine performance and pollutant emissions in a heavy duty DI-diesel engine by CFD modeling, International Journal of Heat and Fluid Flow 33 (2012) 59-69.

[2]. Z. Wu, T. Bao, Q. Zhang, S. Yan, J. Deng, Experimental study on spray combustion characteristics of gasoline-diesel blended fuel in a controllable active thermo-atmosphere, Fuel 135 (2014) 374 - 379.

[3]. T. Sarjovaara, M. Larmi, Dual fuel diesel combustion with an E85 ethanol/gasoline blend, Fuel 139 (2015) $704-714$.

[4]. F. J. Salvador, J. Martínez-López, J. V. Romero, M. D. Roselló, Influence of biofuels on the internal flow in diesel injector nozzles, Mathematical and Computer Modeling 54 (2010), 1699-1705.

[5]. Q. Xue, S. Som, P.K. Senecal, E. Pomraning, LES of fuel spray under non-reacting IC engine conditions, Atomization and Sprays, 23 (10), 925-955, 2013.

[6]. M. Meijer et al., Engine Combustion Network (ECN), Characterization and comparison of boundary conditions for different combustion vessels, Atomization and Sprays 22 (2012) 777-806.

[7]. M. Bardi et al., Engine Combustion Network (ECN), Comparison of Spray Development, Vaporizatin and Combustion in different Combustion Vessels, Atomization and Sprays 22 (2012) 807-842.

[8]. L. M. Pickett et al., Comparison of diesel spray combustion in different high-temperature, high pressure facilities, SAE Paper 2010-01-2106 (2010).

[9]. A. L. Kastengren, F. Z. Tiloco, C. F. Powell, R. Payri, Engine Combustion Network (ECN): Measurements of Nozzle Diameter and Hydraulic Behavior, Atomization and Sprays (2012) doi:10.1615/AtomizSpr.2013006309.

[10]. Z. Luo, M. Plomer, T. Lu, S. Som, D.E. Longman, S.M. Sarathy, W.J. Pitz, A reduced mechanism for biodiesel surrogates for compression ignition engine applications, Fuel 99 (2012) $143-153$.

[11]. S. Som, D.E. Longman, S.M. Aithal, R. Bair, M. Garcia, S.P. Quan, K.J. Richards, P.K. Senecal, A numerical investigation on scalability and grid convergence of internal combustion engine simulations, SAE Paper 2013-01-1095 (2013).

[12]. H. Wang, Y. Ra, M. Jia, R.D. Reitz, Development of a reduced n-dodecane-PAH mechanism and its application for n-dodecane soot predictions, Fuel 136 (2014) 25 -36.

[13]. Y. Pei, W. Liu, M. Mehl, T. Lu, W.J. Pitz, S. Som, A multi-component blend as a diesel fuel surrogate for compression ignition engine applications, Proceedings of the ASME 2014 Internal Combustion Engine Division Fall Technical Conference, ICEF2014-5625, Columbus, IN, October 2014.

[14]. S. Kook, L.M. Pickett, Liquid length and vapor penetration of conventional, FischerTropsch, coal-derived, and surrogate fuel sprays at high-temperature and high-pressure ambient conditions, Fuel, 93 (2012) 539 - 548.

[15]. S. Kook, L.M. Pickett, Soot Volume Fraction and Morphology of Conventional, FischerTropsch, Coal-Derived, and Surrogate Fuel at Diesel Conditions, SAE Int. J. Fuels Lubr. 5(2)(2012) 647-664, doi:10.4271/2012-01-0678.

[16]. R. Payri, J. Gimeno, J. P. Viera, A. H. Plazas, Needle lift profile influence on the vapor phase penetration for a prototype diesel direct acting piezoelectric injector, Fuel, 113 (2013) 257-265.

[17]. R. Payri, J. Gimeno, M. Bardi, and A. H. Plazas, Study liquid length penetration results with a direct acting piezo electric injector, Applied Energy (2013), doi:10.1016/j.apenergy.2013.010.027. 
[18]. J. Benajes, R. Payri, M. Bardi, P. Martí-Aldaraví, Experimental characterization of diesel ignition and lift-off length using a single-hole ECN injector, Applied Thermal Engineering, 58, 1-2, 554-563, ISSN 1359-4311.

[19]. P. M. Lillo, L. M. Pickett, H. Pearson, O. Andersson, S. Kook, Diesel spray ignition detection and spatial/temporal correction, SAE Paper 2012-01-1239 (2012).

[20]. D. L. Siebers, B. S. Higgins, Flame lift-off on direct-injection diesel sprays under quiescent conditions, SAE Paper 2001-01-0530 (2001).

[21]. R. Payri, F. J. Salvador, J. Gimeno, J. de la Morena, Effects of nozzle geometry on direct injection diesel engine combustion process, Applied Thermal Engineering 29 (2009) 2051-2060.

[22]. R. Payri, J. M. Garcia-Oliver, M. Bardi, J. Manin, Fuel temperature influence on diesel sprays in inert and reacting conditions, Applied Thermal Engineering 35 (2012) 185-195.

[23]. L. Michalski, K. Eckersdorf, J. Kucharski, J. McGhee, Temperature measurements, John Wiley \& Sons Ltd., New York, United States of America, 2001.

[24]. V. Macián, V. Bermúdez, R. Payri, J. Gimeno, New technique for determination of internal geometry of a Diesel nozzle with the use of silicone methodology, Experimental Techniques 27 (2003) 39-43.

[25]. B. Higgins, D. Siebers, A. Aradi, Diesel-Spray Ignition and Premixed-Burn Behavior, SAE Technical Paper 2000-01-0940 (2000), doi:10.4271/2000-01-0940.

[26]. G. S. Settles, Schlieren and sadowgraph techniques: visualizing phenomena in transparent media (Experimental Fluid Mechanic), Springer Verlag, Heidelberg, Germany, 2001.

[27]. L.M. Pickett, S. Kook, T. Williams, Visualization of Diesel Spray Penetration, Cool-Flame, Ignition, High-Temperature Combustion, and Soot Formation Using High-Speed Imaging, SAE Int. J. Engines 2(1): 439-459, 2009, doi:10.4271/2009-01-0658.

[28]. J. Naber, D. Siebers, Effects of gas density and vaporization on penetration and dispersion of diesel sprays, SAE Paper 960034 (1996).

[29]. R. Klein-Douwel, P. Fritjers, L. Somers, W. de Boer, R. Baert, Macroscopic diesel fuel spray shadowgraphy using high speed digital imaging in a high pressure cell, Fuel 86 (2007) 1994-2007.

[30]. S. Parrish, R. Zink, Development and application of an imaging system to evaluate liquid and vapor envelopes of sprays from a multi-hole gasoline fuel injector operating under engine-like conditions, Atomization and Sprays 22 (2012) 647-661.

[31]. D. L. Siebers, Liquid-Phase Fuel Penetration in Diesel Sprays, SAE International 980809 (1998).

[32]. CONVERGE 2.1.0 Theory Manual, Convergent Science, Inc., Middleton, WI, 2013.

[33]. P. Kundu, Y. Pei, M. Wang, M. Raju, S. Som, Evaluation of turbulence-chemistry interaction under diesel engine conditions with multi-flamelet RIF model, Atomization and Spray, 24 (9) (2014), 779-800.

[34]. R.D. Reitz, R. Diwakar, Structure of high-pressure fuel sprays, SAE Paper, 870598 (1987).

[35]. R.D. Reitz, Modeling atomization processes in high pressure vaporizing sprays, Atomization and Spray Technology, 3 (1987) 309 - 337.

[36]. M.A. Patterson, R.D. Reitz, Modeling the effects of fuel spray characteristics on diesel engine combustion and emissions, SAE Paper, 980131 (1998).

[37]. D.P. Schmidt, C.J. Rutland, A new droplet collision algorithm, Journal of Computational Physics, 164 (2000) $62-80$.

[38]. N. Frossling, Evaporation, heat transfer, and velocity distribution in two-dimensional and rotationally symmetrical laminar boundary-layer flow, N.A.C.A., 168: AD-B189, 1956.

[39]. A.B. Liu, D.K. Mather, R.D. Reitz, Modeling the effects of drop drag and breakup on fuel sprays, SAE Paper, 930072 (1993).

[40]. Z. Han, R.D. Reitz, Turbulence modeling of internal combustion engines using RNG k- $\varepsilon$ models, Combust. Sci. and Tech.106 (1995), 267-295. 
[41]. P.K. Senecal, E. Pomraning, K.J. Richards, S. Som, Grid-Convergent Spray Models for Internal combustion engine CFD simulations, Journal of Energy Resources Technology 136 (1) (2013), 12204.

[42]. H. Pitsch, M. Chen, N. Peters, Unsteady flamelet modelling of turbulent hydrogen-air diffusion flames, Twenty-Seventh Symposium (International) of the Combustion Institute, (1998), 1057-1064.

[43]. M. Huber, personal communication, 2013.

[44]. E.R. Hawkes, Y. Pei, C. Angelberger, M. Bardi, ECN2 proceedings, ECN2: Ignition and Lift-off Length, 2012, Germany.

[45]. Y. Pei, E.R. Hawkes, S. Kook, Transported probability density function modelling of the vapour phase of an n-heptane jet at diesel engine conditions, Proc. Combust. Inst., 34 (2) (2013) 3039-3047.

[46]. Y. Pei , E.R. Hawkes, S. Kook, G.M. Graham, T. Lu, Modelling n-dodecane spray and combustion with the transported probability density function method, Combust. Flame, 2014, submitted.

[47]. D. Siebers, Liquid-Phase Fuel Penetration in Diesel Sprays, SAE Technical Paper 980809 (1998), doi:10.4271/980809.

[48]. L.M. Pickett, D. Siebers, C. Idicheria, Relationship between ignition processes and the lift-off length of diesel fuel jets, SAE Technical Paper 2005-01-3843 (2005), doi:10.4271/2005-01-3843.

[49]. E.R. Hawkes, Y. Pei, S. Kook, S. Som, An analysis of the structure of an n-dodecane spray flame using PDF modeling, Proceedings of the Australian Combustion Symposium, Nov. 6-8, 2013.

[50]. Y. Pei, PhD thesis, Transported PDF modeling of spray combustion at practical diesel engine conditions, 2013, Sydney, UNSW. 


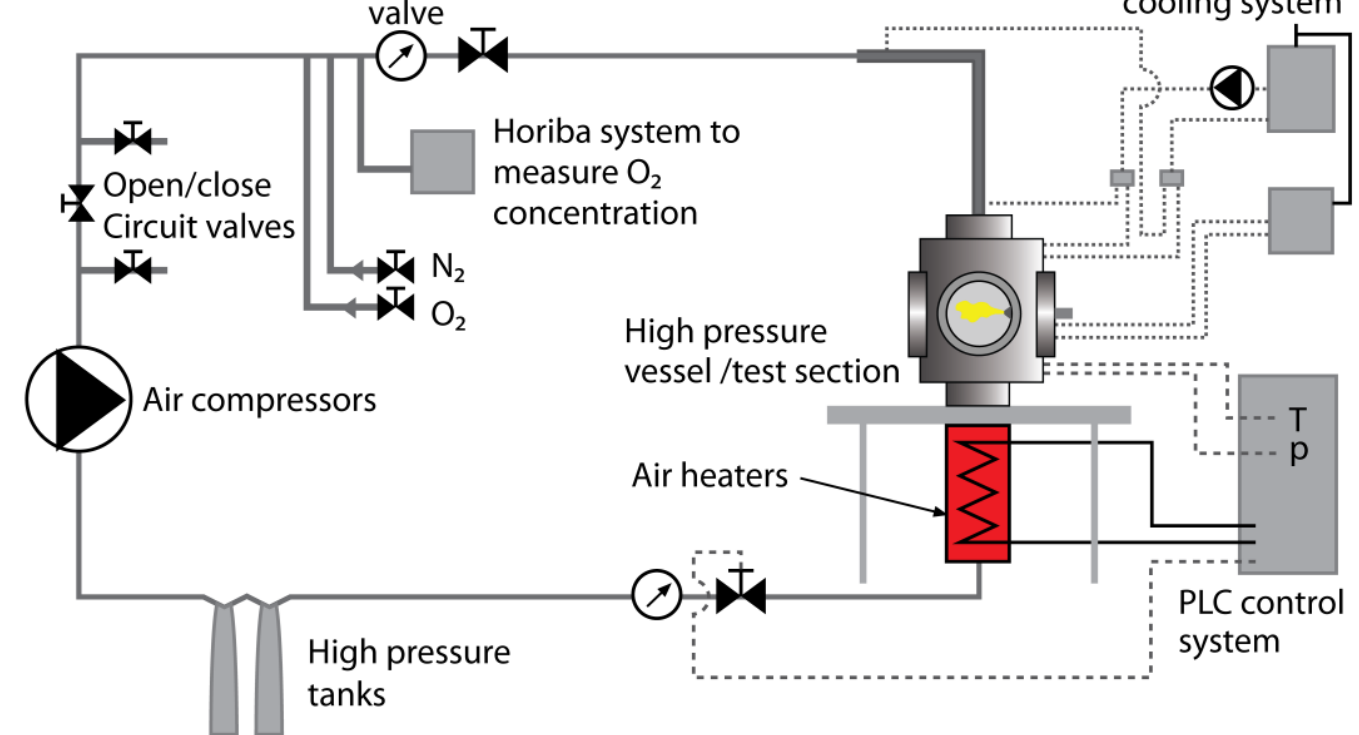

Figure 1: Schematic of the experimental facility. 


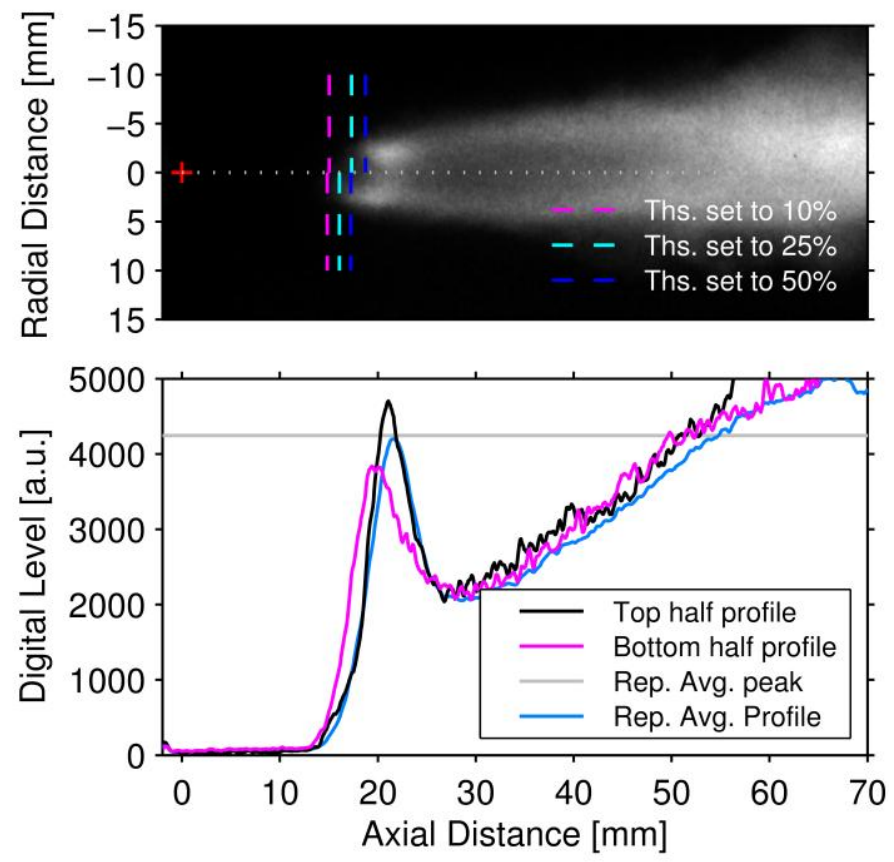

Figure 2: Raw $\mathrm{OH}^{\star}$ chemiluminescence image obtained from a single injection (top) and intensity profiles constructed from the two halves of the image (bottom), utilized to estimate the LOL. The particular case shown is under Spray A conditions. 


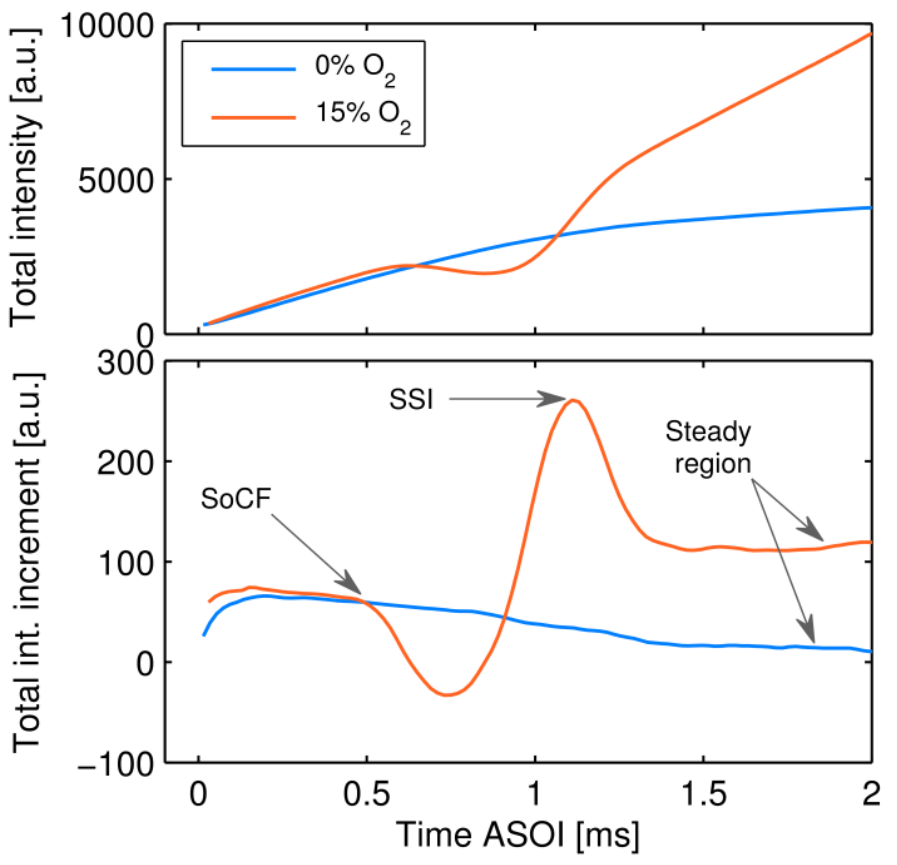

Figure 3: Total image intensity (top) and total image intensity increment (bottom) for both an inert and a reactive spray. Although inert spray results are not presented in this paper, the corresponding inert spray is presented in this figure as a reference for comparison. In this case, the chamber temperature is $900 \mathrm{~K}$, chamber density is $15.2 \mathrm{~kg} / \mathrm{m}^{3}$, and the injection pressure is 500 bar. 


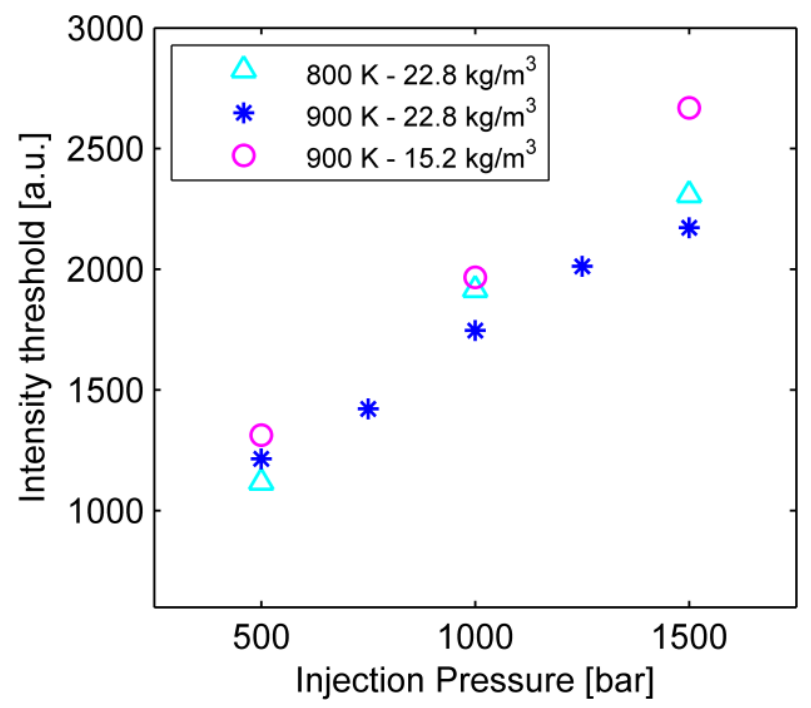

731

Figure 4: Intensity thresholds for different injection pressures, two ambient temperatures and two densities. 

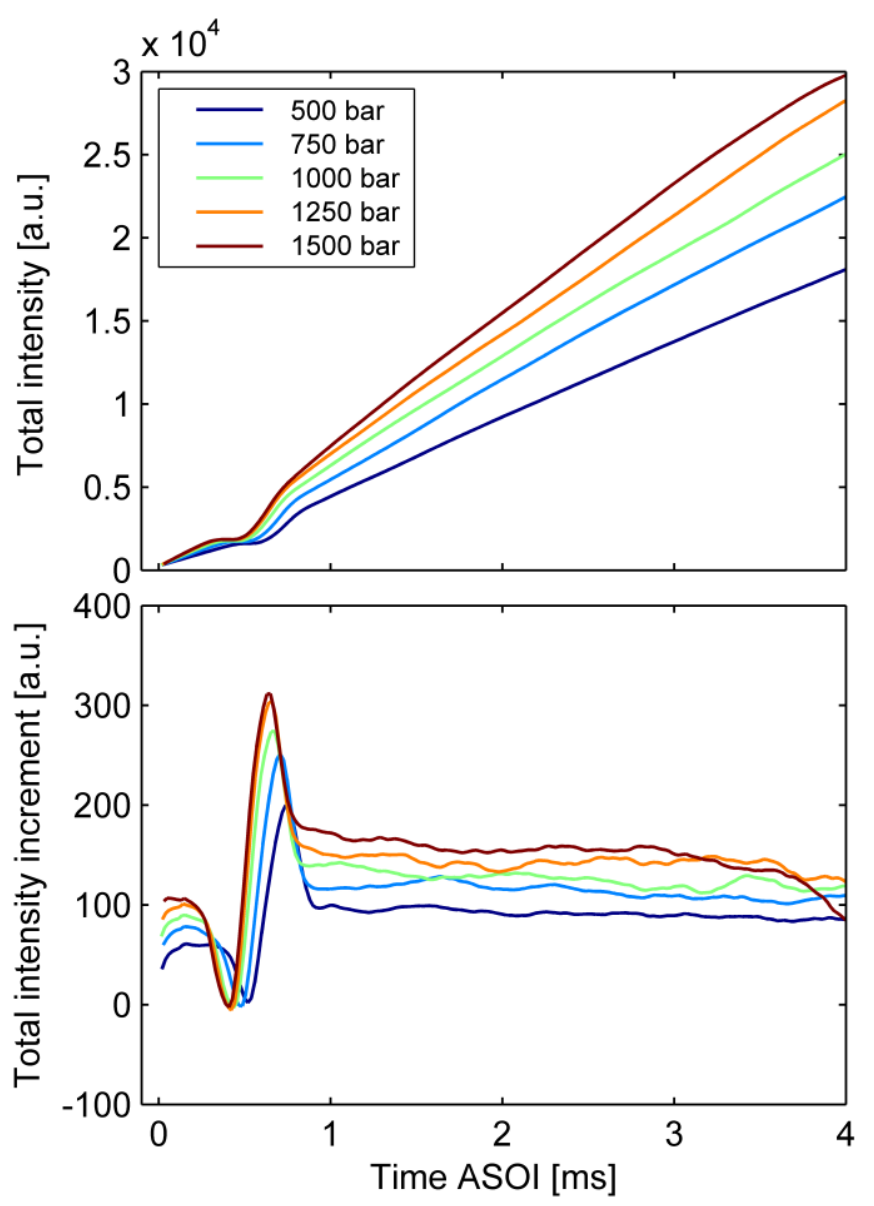

Figure 5: Total spray intensity (top) and intensity increment (bottom) for different injection pressures. Except for injection pressure, the rest of the test conditions correspond to that of Spray A. 

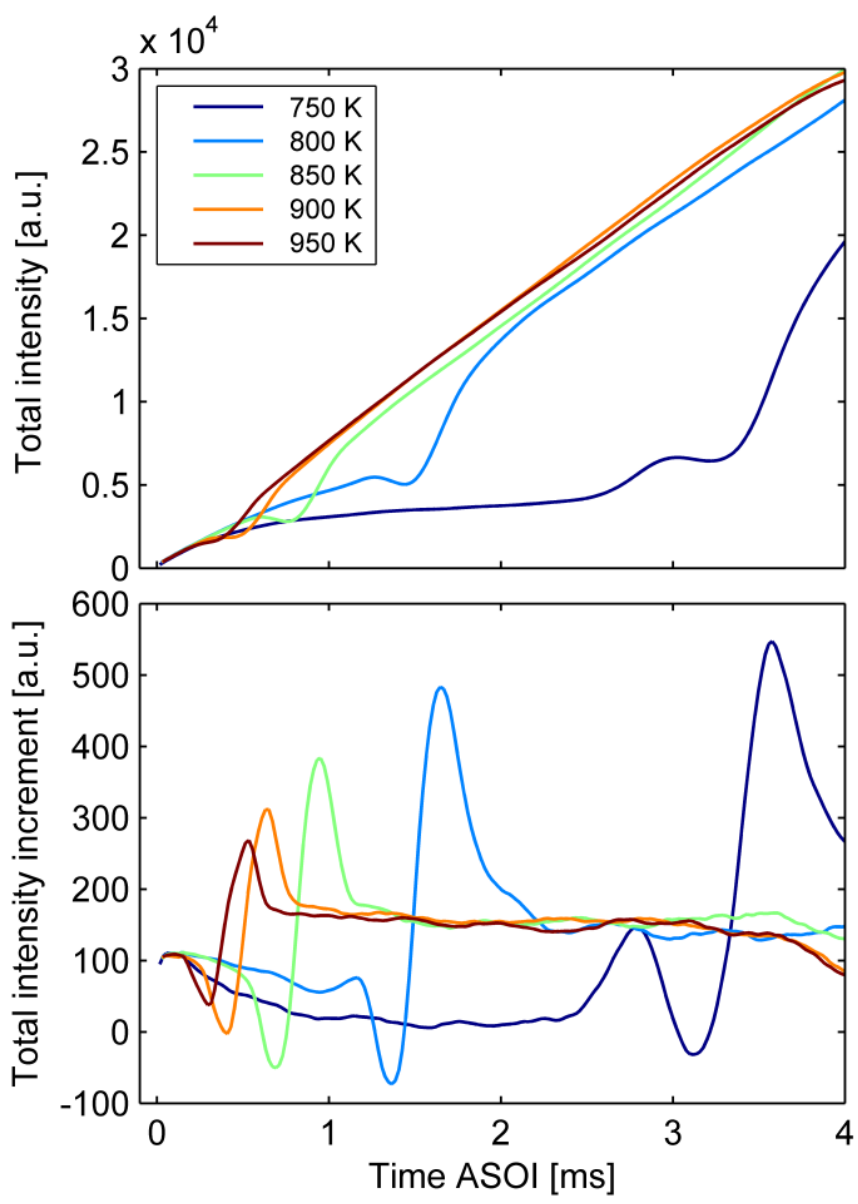

Figure 6: Total spray intensity (top) and intensity increment (bottom) for different ambient temperatures. Except for the ambient temperature, the rest of the test conditions correspond to that of Spray A. 

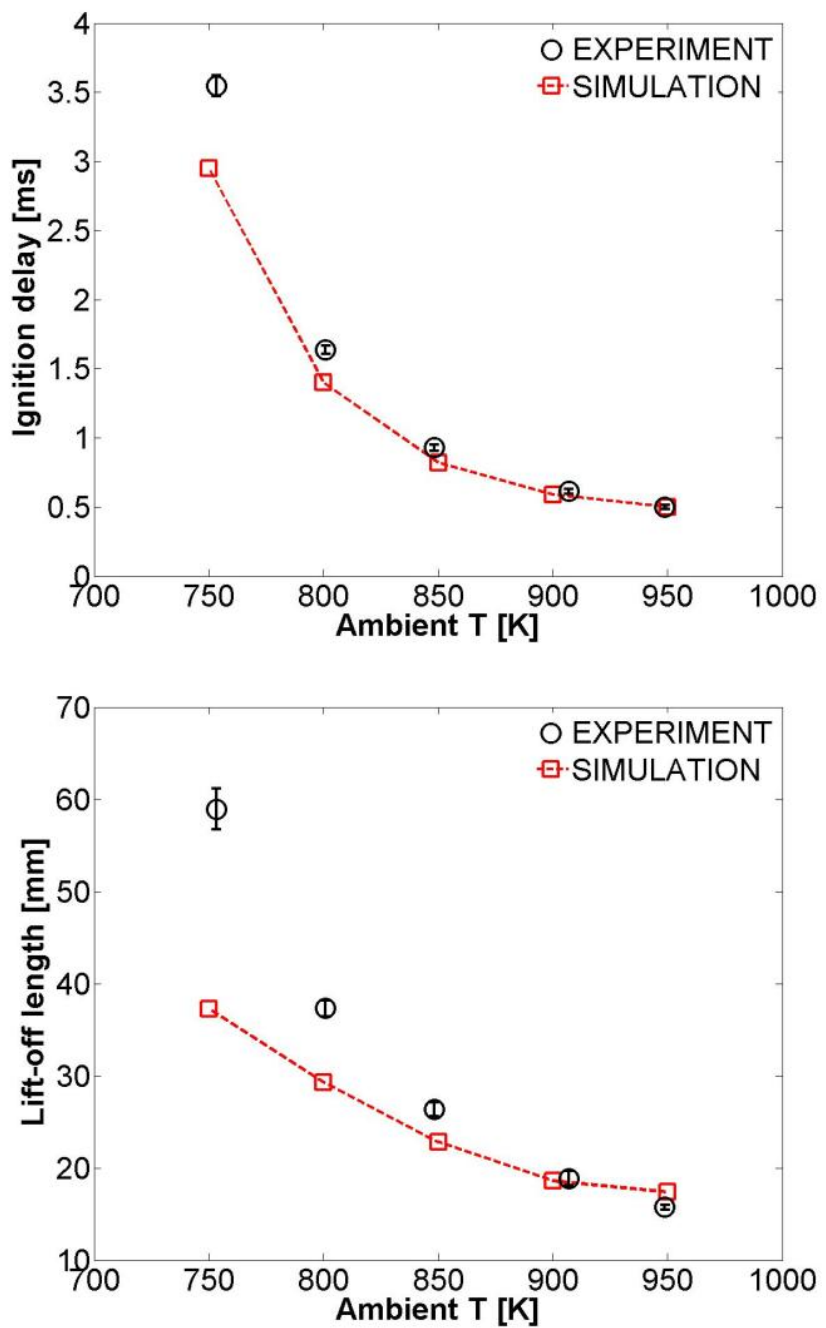

Figure 7: Comparison of ignition delay (top) and lift-off length (bottom) between experiment and simulation at different ambient temperature conditions shown in Table 1. Except for the ambient temperature, the rest of the test conditions correspond to that of Spray A. 

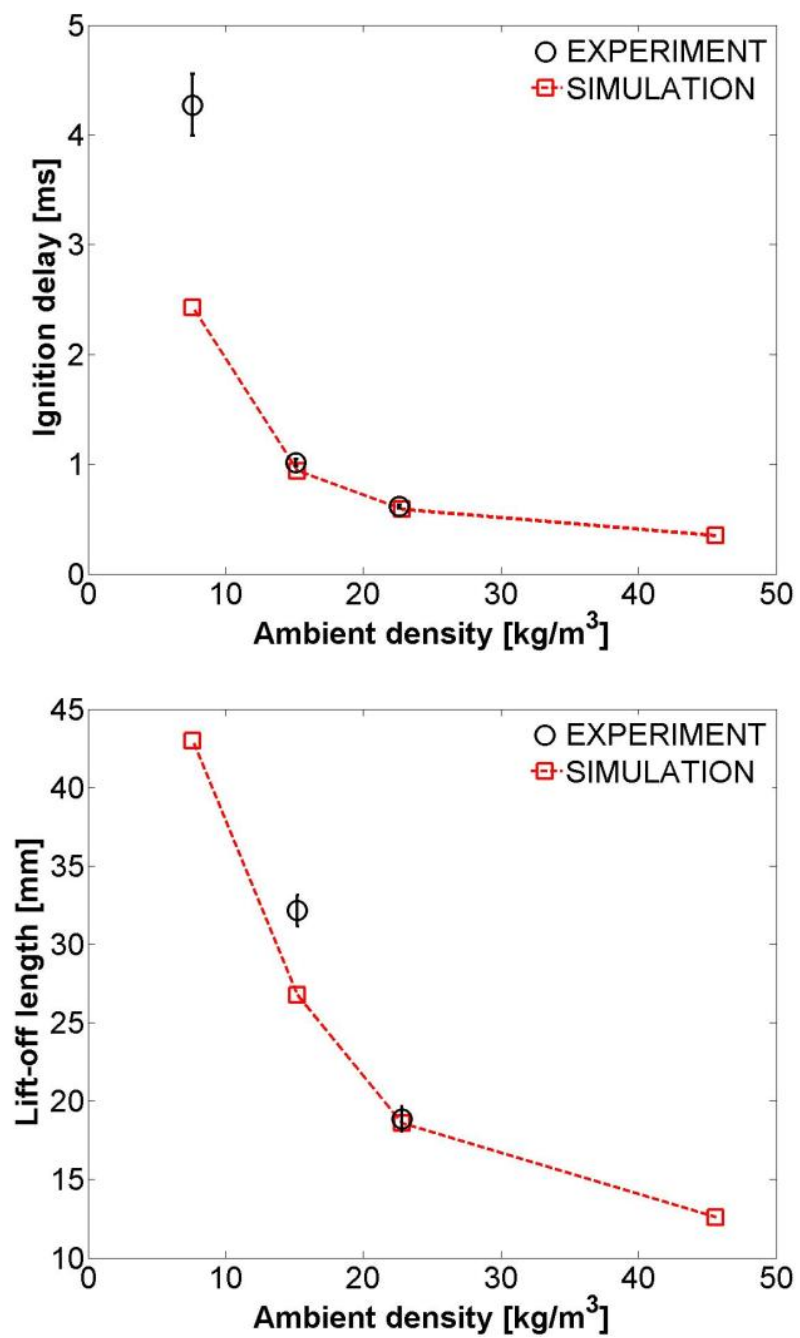

Ambient density $\left[\mathrm{kg} / \mathrm{m}^{3}\right]$

Figure 8: Comparison of ignition delay (top) and lift-off length (bottom) between experiment and simulation at different ambient density conditions shown in Table 1. Except for the ambient density, the rest of the test conditions correspond to that of Spray A. 

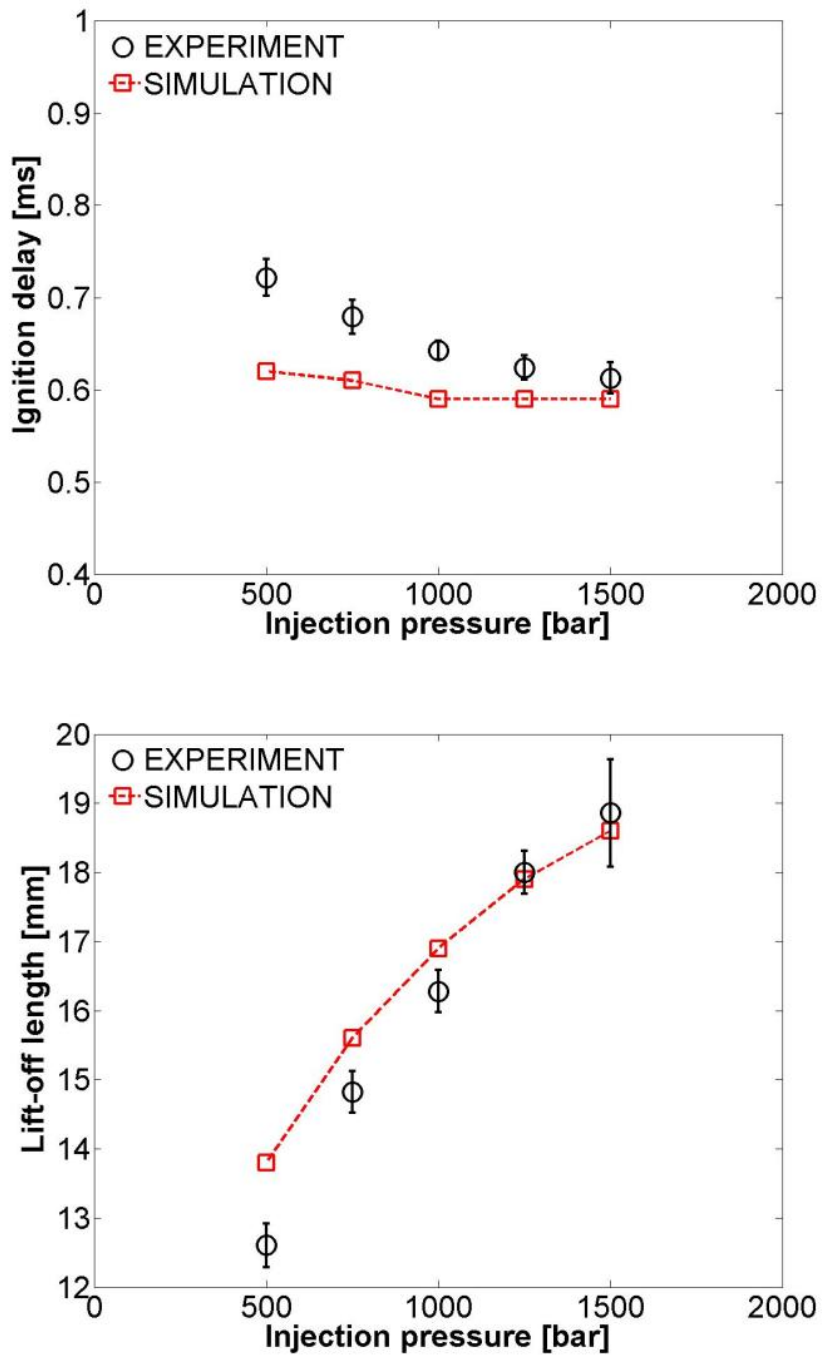

Figure 9: Comparison of ignition delay (top) and lift-off length (bottom) between experiment and simulation at different injection pressure conditions shown in Table 1. Except for the injection pressure, the rest of the test conditions correspond to that of Spray A. 


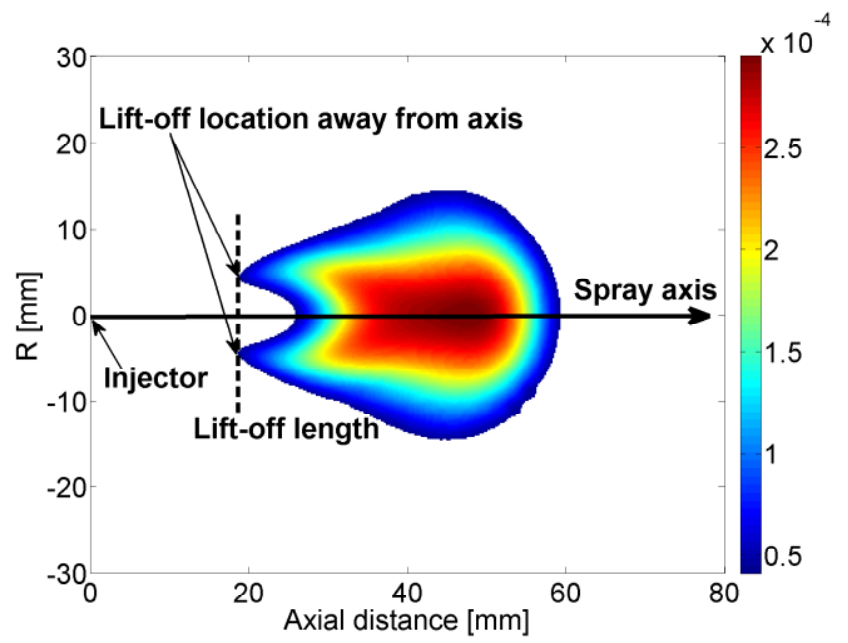

Figure 10: Flame structure (OH mass fraction) at Spray A $900 \mathrm{~K}$ condition at $3.2 \mathrm{~ms}$ from SOI. 


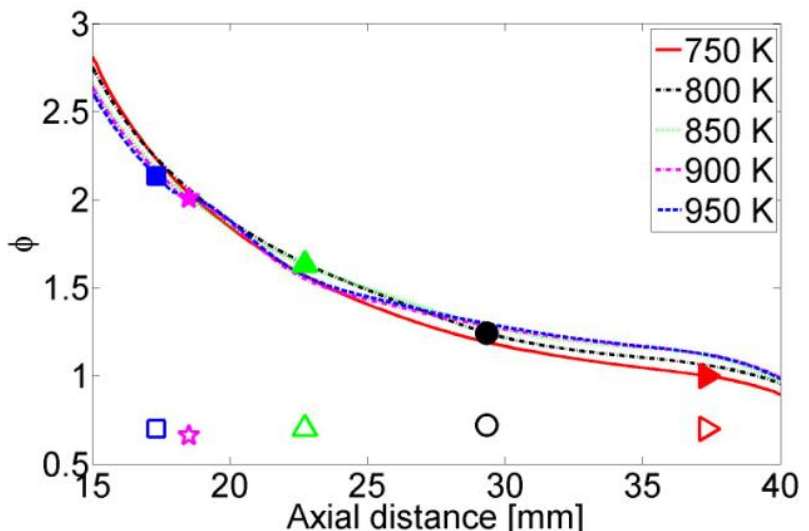

Figure 11: Axial equivalence ratio along the jet centerline at different ambient temperature conditions. Solid markers represent the axial lift-off locations and hollow markers are the equivalence ratio at the lift-off locations away from the axis. Except for the ambient temperature, the rest of the test conditions correspond to that of Spray A. 


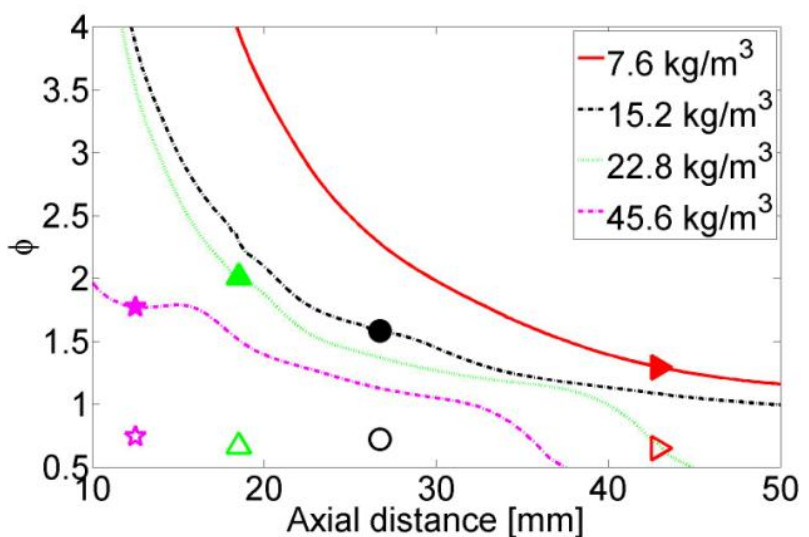

Fure 12: Axial equivalence ratio along the jet centerline at different ambient density conditions. Solid markers represent the axial lift-off locations and hollow markers are the equivalence ratio at the lift-off locations away from the axis. Except for the ambient density, the rest of the test conditions correspond to that of Spray A. 


\section{Figure Captions}

Figure 1: Schematic of the experimental facility.

Figure 2: Raw $\mathrm{OH}^{*}$ chemiluminescence image obtained from a single injection (top) and intensity profiles constructed from the two halves of the image (bottom), utilized to estimate the LOL. The particular case shown is under Spray A conditions.

Figure 3: Total image intensity (top) and total image intensity increment (bottom) for both an inert and a reactive spray. Although inert spray results are not presented in this paper, the corresponding inert spray is presented in this figure as a reference for comparison. In this case, the chamber temperature is $900 \mathrm{~K}$, chamber density is $15.2 \mathrm{~kg} / \mathrm{m}^{3}$, and the injection pressure is 500 bar.

Figure 4: Intensity thresholds for different injection pressures, two ambient temperatures and two densities.

Figure 5: Total spray intensity (top) and intensity increment (bottom) for different injection pressures. Except for injection pressure, the rest of the test conditions correspond to that of Spray A.

Figure 6: Total spray intensity (top) and intensity increment (bottom) for different ambient temperatures. Except for the ambient temperature, the rest of the test conditions correspond to that of Spray A.

Figure 7: Comparison of ignition delay (top) and lift-off length (bottom) between experiment and simulation at different ambient temperature conditions shown in Table 1. Except for the ambient temperature, the rest of the test conditions correspond to that of Spray A.

Figure 8: Comparison of ignition delay (top) and lift-off length (bottom) between experiment and simulation at different ambient density conditions shown in Table 1. Except for the ambient density, the rest of the test conditions correspond to that of Spray A.

Figure 9: Comparison of ignition delay (top) and lift-off length (bottom) between experiment and simulation at different injection pressure conditions shown in Table 1. Except for the injection pressure, the rest of the test conditions correspond to that of Spray A.

Figure 10: Flame structure (OH mass fraction) at Spray A $900 \mathrm{~K}$ condition at $3.2 \mathrm{~ms}$ from SOI.

Figure 11: Axial equivalence ratio along the jet centerline at different ambient temperature conditions. Solid markers represent the axial lift-off locations and hollow markers are the equivalence ratio at the lift-off locations away from the axis. Except for the ambient temperature, the rest of the test conditions correspond to that of Spray A.

Figure 12: Axial equivalence ratio along the jet centerline at different ambient density conditions. Solid markers represent the axial lift-off locations and hollow markers are the equivalence ratio at the lift-off locations away from the axis. Except for the ambient density, the rest of the test conditions correspond to that of Spray A. 
826 Table 1: Test conditions summary. The test conditions highlighted correspond to ECN Spray A 827 conditions.

828

\begin{tabular}{lll}
\hline Parameter & Values & Units \\
\hline Fuel & SR23 & - \\
Orifice diameter $\left(D_{0}\right)$ & 0.089 & $\mathrm{~mm}$ \\
k-factor $^{2}$ & 1.5 & - \\
Energizing time & 4000 & $\mu \mathrm{s}$ \\
Tip temperature & 390 & $\mathrm{~K}$ \\
Gas density $\left(\rho_{a}\right)$ & $7.6,15.2, \mathbf{2 2 . 8}$ & $\mathrm{kg} / \mathrm{m}^{3}$ \\
Gas temperature $\left(T_{\text {amb }}\right)$ & $750,800,850,900,950$ & $\mathrm{~K}$ \\
Injection pressure $\left(p_{\text {rail }}\right)$ & $500,750,1000,1250,1500$ & $\mathrm{bar}$ \\
Oxygen concentration & $15 \%$ & - \\
\hline${ }^{2}$ k-factor definition is given by Macian et al.[24]. &
\end{tabular}


Table 2. Details of the optical setup used in the study.

\begin{tabular}{|c|c|c|}
\hline & $\begin{array}{l}\text { Schlieren } \\
\text { Imaging }\end{array}$ & $\mathrm{OH}^{*}$ chemilum. \\
\hline Camera & Photron SA-5 & Andor - Istar \\
\hline $\begin{array}{l}\text { Sensor } \\
\text { Type }\end{array}$ & CMOS & ICCD \\
\hline Lens & $50 \mathrm{~mm}$ & $100 \mathrm{~mm}$ - U.V. \\
\hline Diaphragm & $4 \mathrm{~mm}$ & - \\
\hline Filter & - & $310 \mathrm{cwl} \pm 5 \mathrm{~nm}$ \\
\hline Frame Rate & $50 \mathrm{kfps}$ & 1 frame/injection \\
\hline $\begin{array}{c}\text { Shutter } \\
\text { time }\end{array}$ & $4 \mu \mathrm{s}$ & $\begin{array}{c}3 \mathrm{~ms} \text { (from } 2 \text { to } \\
5 \mathrm{~ms} \text { ASOI) }\end{array}$ \\
\hline Repetitions & 8 & 8 \\
\hline $\begin{array}{c}\text { Spatial } \\
\text { resolution }\end{array}$ & 5.27 pix $/ \mathrm{mm}$ & $11.76 \mathrm{pix} / \mathrm{mm}$ \\
\hline
\end{tabular}

